\title{
ロバスト UKFとそのパラメータ設計手法*
}

金田 $\quad$ 泰昌 ${ }^{\ddagger} \cdot \lambda$ 月 康晴

\section{Robust UKF and Design Method of Its Parameters*}

Yasuaki KANEDA $^{\dagger \ddagger}$, Yasuharu IRIZUKI ${ }^{\ddagger}$ and Masaki YAMAKITA ${ }^{\dagger}$

\section{1. はじめに}

近年，超音波センサやレーダ計測，画像計測といった 非接触型の計測手法を用いたシステムが注目を集めてい るが , これらの計測方法は外界の影響により外れ值が生 じることが知られている．乥して，これらの外れ值は状 態推定精度や制御性能に悪影響を及ぼす。

外れ值の除去手法として , ロバストカルマンフィルタ (RKF) とよばれる, 非ガウスノイズに対応したカルマ ンフィルタがこれまでに提案されている．光の中でも近 年, $l_{1}$ 正則化を用いた RKF が注目されている $[1-3] . l_{1}$ 正則化はあるしきい値に従ってスパースな解を与える手 法であり，外れ值をスパースな解と見なすことでしきい 值処理をすることができる . 文献 [1] では線形 RKF が提 案されおり，文献 [2] では光のパラメータ設計手法が提 案されている.また，文献 [3]では, $l_{1}$ ラプラス事前分 布を用いた最大事後確率推定 (MAP 推定) を解くこと で , 非線形ロバストフィルタを実現している .

本論文では, 文献 $[1,2]$ を UKF [4] に拡張することで非 線形 RKF を構築する. 光して，光のパラメータ設計手 法を提案する . 文献 [3] では状態の共分散行列が更新さ れず一定であったが，提案手法を用いることで状態の共 分散行列が更新されるという利点がある.また, 最適化 問題の次元が低次元化される利点もある .

\section{2. ロバスト UKFとその設計手法}

$2.1 l_{1}$ 正則化を用いたロバスト UKF の概要 $l_{1}$ 正則化を用いた RKF は, 状態の更新則として以下 の最適化問題を解く手法である $[1,2]$.

\footnotetext{
* 原稿受付 2012 年 12 月 5 日

†東京工業大学 大学院 理工学研究科 Graduate School of Science and Engineering, Tokyo Institute of Technology; 2-12-1, Ohokayama, Meguro-ku, Tokyo 152-8552, JAPAN

‡東京都立産業技術研究センター Tokyo Metropolitan Industrial Technology Research Institute; 2-4-10, Aomi, Koutou-ku, Tokyo 135-0064, JAPAN
}

Key Words: robust Kalman filter, UKF, regularization parameter design, $l_{1}$ Laplace distribution.

$$
\begin{gathered}
\min _{x_{k}, z_{k}} v_{k}^{T} R^{-1} v_{k}+\left(x_{k}-\hat{x}_{k \mid k-1}\right)^{T} P^{-1}\left(x_{k}-\hat{x}_{k \mid k-1}\right) \\
+\sum_{i=1}^{m} \lambda_{i}\left|\left(z_{k}\right)_{i}\right| \\
\text { subject to } y_{k}=h\left(x_{k}\right)+v_{k}+z_{k}, \\
x_{k}=\hat{x}_{k \mid k-1}+L\left(e_{k}-z_{k}\right) \\
e_{k}=y_{k}-h\left(\hat{x}_{k \mid k-1}\right)
\end{gathered}
$$

ここで, $L$ はカルマンゲインを表す . また,$v_{k} \in \mathbb{R}^{m}$ は 時刻 $k$ における観測ガウスノイズを， $P \in \mathbb{R}^{n \times n}$ および $R \in \mathbb{R}^{m \times m}$ はとれ光れ状態および観測ガウスノイズ $v_{k}$ の共分散行列を表す.また， $z_{k} \in \mathbb{R}^{m}$ は時刻 $k$ における 外れ值を表し，(1) 式の解として与えられる． $\lambda_{i}$ は正則 化パラメータであり，通常対象に合わせて試行錯誤的に 決める必要がある。

更新則 (1) 式において , カルマンゲイン $L$ の計算を UKF[4] で行ったものがロバスト UKF (RUKF) である .

\subsection{RUKF のパラメータ設計手法}

いま, 外れ值 $z_{k}$ が次式で表される平均値 0 , 共分散行 列 $R_{l}$ の $l_{1}$ ラプラス分布に従うと仮定する .

$$
p_{z_{k}}\left(z_{k}\right)=\operatorname{det}\left(2 R_{l}\right)^{-1 / 2} \exp \left[-\sqrt{2}\left\|R_{l}^{-1 / 2} z_{k}\right\|_{1}\right]
$$

この $l_{1}$ ラプラス分布を事前分布としたときの MAP 推 定を考えると, MAP 推定から得られる最適化問題の構 造の中に $l_{1}$ 正則化項が現れる $[3]$. この性質を利用し， MAP 推定の枠組みから RKF を再導出する .

ベイズの公式より，観測值 $y_{k}$ が与えられたときの $x_{k}$ の事後確率分布 $p\left(x_{k} \mid y_{k}\right)$ は次式で与えられる .

$$
p\left(x_{k} \mid y_{k}\right)=\frac{p\left(y_{k} \mid x_{k}\right) p\left(x_{k}\right)}{p\left(y_{k}\right)} \propto p\left(y_{k} \mid x_{k}\right) p\left(x_{k}\right)
$$

$\mathrm{UKF}$ の問題設定の仮定より, $x_{k}$ は近似的に平均 $\hat{x}_{k \mid k-1}$, 共分散行列 $P$ の正規分布 $p_{x_{k}}\left(x_{k}\right)$ に従う. また, 出力方 程式が次式の非線形方程式で与えられるとする .

$$
y_{k}=h\left(x_{k}\right)+v_{k}+z_{k}
$$

ただし, $v_{k}$ は平均 0 , 共分散行列 $R$ の観測ガウス分布 $p_{v_{k}}\left(v_{k}\right)$ に従う $\cdot v_{k}$ と $z_{k}$ は互いに独立であると仮定する と, 状態 $x_{k}$ が与えられたときの条件付き確率密度関数 
$p\left(y_{k} \mid x_{k}\right)$ は, 以下の畳み込み積分で与えられる .

$$
\begin{aligned}
& p\left(y_{k} \mid x_{k}\right)=\int_{-\infty}^{\infty} p_{z_{k}}\left(h\left(x_{k}\right)-y_{k}-v_{k}\right) p_{v_{k}}\left(v_{k}\right) d v_{k} \\
& \text { て } \\
& p\left(y_{k} \mid x_{k}\right) p_{x_{k}}\left(x_{k}\right)= \\
& \quad \int_{-\infty}^{\infty} p_{z_{k}}\left(h\left(x_{k}\right)-y_{k}-v_{k}\right) p_{v_{k}}\left(v_{k}\right) p_{x_{k}}\left(x_{k}\right) d v_{k}
\end{aligned}
$$$$
\text { よって , }
$$

また, 確率密度関数は常に正である. 炎のため, (2) 式 を最大化することは (4) 式の被積分関数を最大化するこ とと等価である．㫕して，この最大化問題は次式の最小 化問題と等価である .

$$
\begin{array}{r}
\min _{x_{k}, z_{k}} v_{k}^{T} R^{-1} v_{k}+\left(x_{k}-\hat{x}_{k \mid k-1}\right)^{T} P^{-1}\left(x_{k}-\hat{x}_{k \mid k-1}\right) \\
+2 \sqrt{2}\left\|R_{l}^{-1 / 2} z_{k}\right\|_{1}
\end{array}
$$

一方， $\Lambda=\operatorname{diag}\left(\lambda_{1}, \cdots, \lambda_{m}\right)$ とすると，(1) 式を次式のよ うに書き直すことができる．

$$
\begin{gathered}
\min _{x_{k}, z_{k}} v_{k}^{T} R^{-1} v_{k}+\left(x_{k}-\hat{x}_{k \mid k-1}\right)^{T} P^{-1}\left(x_{k}-\hat{x}_{k \mid k-1}\right) \\
+\left\|\Lambda z_{k}\right\|_{1}
\end{gathered}
$$

よって，(5),(6) 式を比較すると，(6) 式は $l_{1}$ ラプラス分 布の共分散行列 $R_{l}$ の対角成分のみを考慮した MAP 推定 とみなすことができる。したがって， $R_{l}^{-1 / 2}$ の対角成分 を $r_{i}$ とすると, 正則化パラメータは次式で与えられる .

$$
\lambda_{i}=2 \sqrt{2} r_{i}
$$

これは, $l_{1}$ ラプラス分布の共分散行列 $R_{l}$ が推定できれ ば，正則化パラメータが自動的に決まることを意味する．

$R_{l}$ の最も簡単な推定方法は, 出力のサンプル点から出 力の共分散行列を計算する方法である. 乥こで, 本研究 ではシグマポイントを用いて $R_{l}$ を推定する .すなわち，

$$
R_{l}=R+\sum_{i=0}^{2 n} W_{i}\left(\mathcal{Y}_{i}-\hat{y}\right)\left(\mathcal{Y}_{i}-\hat{y}\right)^{T}
$$

ただし,$W_{i}$ はシグマポイントの重み , $\mathcal{Y}_{i}$ はシグマポイ ントからの推定出力, 光して $\hat{y}$ は弚の平均值である .

(注意 1 ) 提案手法では $l_{1}$ ラプラス分布の共分散行列 をシグマポイントを用いて推定し，(7) 式でパラメータを 計算する .これは, 通常のUKF の設計を行えばRUKF のパラメータが自動的に決定されることを意味する .

(注意 2) 提案手法ではUKF と最小化問題を組み合わ せることでロバストフィルタを実現している．一方，(5) 式を直接解くことで, UKF を用いずに非線形ロバス卜 フィルタを実現できる.事実，文献 [3]では，MAP 推定 から得られた最小化問題を直接解いている．しかしなが ら，UKF を用いることで，(5) 式 内の共分散行列を更 新することができる. 兴のため, 提案手法はパラメータ 変動に対して適応的になっているといえる.

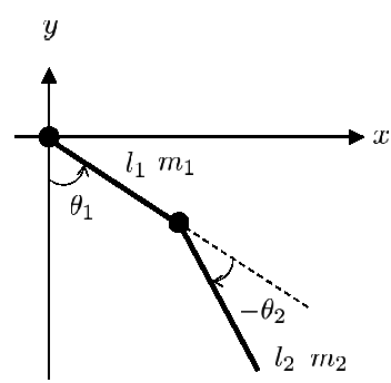

Fig. 1 Model of a two-link manipulator

(注意 3 ) 提案手法では最小分散推定值が $x_{k}=\hat{x}_{k \mid k-1}+$ $L\left(e_{k}-z_{k}\right)$ の形として与えられるという事実から，これ を $x_{k}$ に関する拘束条件として用いている . 兴のため, (1) 式は実際には $z_{k}$ のみに関する最小化問題となる .つ まり, (5) 式を直接解く手法に比べ, 提案手法の最小化 問題は状態の数だけ低次元化されていることになる.

\section{3. 数值シミュレーション}

\section{1 モデル}

Fig. 1 に示した 2 リンクマニピュレータの状態推定問 題を考える.いま，一般化座標を $q=\left[\theta_{1}, \theta_{2}\right]^{T}$ とし，質 量中心はリンク先端にあるとする . また , 慣性モーメン トおよびリンクの粘性はゼロとする .このとき 2 リンク マニピュレータの動特性は次式で与えられる .

$$
M(q) \ddot{q}+C(q, \dot{q})+G(q)=\tau
$$
ただし，

$$
\begin{aligned}
& M(q)=\left[\begin{array}{cc}
\alpha+\gamma+2 \beta \sin \theta_{2} & \gamma+\beta \sin \theta_{2} \\
\gamma+\beta \sin \theta_{2} & \gamma
\end{array}\right], \\
& C(q, \dot{q})=\left[\beta\left(2 \dot{\theta}_{1}+\dot{\theta}_{2}\right) \dot{\theta}_{2} \cos \theta_{2}-\beta \dot{\theta}_{1}^{2} \cos \theta_{2}\right]^{T} \text {, } \\
& G(q)=\left[\begin{array}{c}
\left(m_{1}+m_{2}\right) g l_{1} \sin \theta_{1}+m_{2} g l_{2} \sin \left(\theta_{1}+\theta_{2}\right) \\
m_{2} g l_{2} \sin \left(\theta_{1}+\theta_{2}\right)
\end{array}\right], \\
& \alpha=m_{1} l_{1}^{2}+m_{2} l_{2}^{2}, \quad \beta=m_{2} l_{1} l_{2}, \quad \gamma=m_{2} l_{2}^{2}
\end{aligned}
$$

また , 出力は手先の $x, y$ 座標とする . すなわち，

$$
y=\left[\begin{array}{c}
l_{1} \sin \theta_{1}+l_{2} \sin \left(\theta_{1}+\theta_{2}\right) \\
-l_{1} \cos \theta_{1}-l_{2} \cos \left(\theta_{1}+\theta_{2}\right)
\end{array}\right]
$$

モデルのパラメータは $, l_{1}=1.0, l_{2}=2.0, m_{1}=0.5$, $m_{2}=0.5$ である. また, 初期值は $x_{0}=[1.4,0,0,0]^{T}$ であ り，各リンクの入力はゼロとする .

観測ガウスノイズのパラメータは以下の通りである .

$$
E[v]=0, \quad E\left[v v^{T}\right]=0.25 I
$$

ここで, $I$ は単位行列を表す．また，ごくまれにセンサ に異常値が混入する場合を考え, 外れ值のモデルは裾の 広い分布を持つコーシー分布を仮定する .コーシー分布 の確率密度関数は次式で表され，インパルス的なセンサ ノイズを表す際にしばしば用いられる $[5]$. 


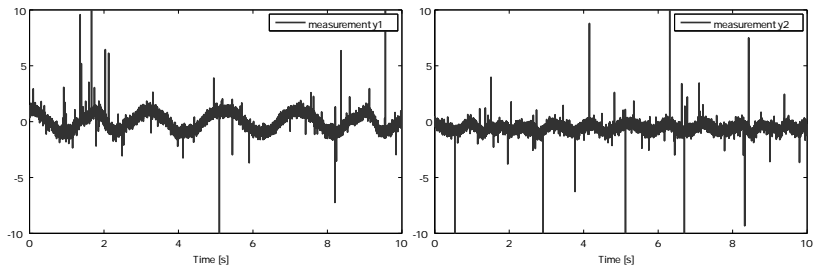

(a) $y_{1}$

(b) $y_{2}$

Fig. 2 Measurements of position outputs

Table 1 Mean squared error of estimates

\begin{tabular}{|l|c|c|c|c|}
\hline & $\theta_{1}$ & $\theta_{2}$ & $\dot{\theta}_{1}$ & $\dot{\theta}_{2}$ \\
\hline \hline UKF & $2.36 \times 10^{-1}$ & $6.76 \times 10^{-1}$ & 21.1 & 57.7 \\
\hline robust filter & $9.98 \times 10^{-1}$ & $9.92 \times 10^{-1}$ & 19.4 & 34.8 \\
\hline RUKF & $3.97 \times 10^{-2}$ & $1.23 \times 10^{-1}$ & 2.13 & 6.32 \\
\hline
\end{tabular}

$$
p_{c}(x)=\frac{1}{\pi} \frac{\delta}{\delta^{2}+\left(x-x_{0}\right)^{2}}
$$

ただし， $x_{0}=0 ， \delta=1.0 \times 10^{-2}$ とする.

UKF および RUKF に用いる観測ノイズの共分散行 列は既知とし，他のパラメータは以下のように設定する .

$$
P_{0 \mid 0}=10 I, \quad Q=10^{-4}, \quad \kappa=1
$$

\section{2 結果}

Fig. 2 に観測値を，Fig. 3 および Fig. 4 にUKF お よびRUKF による推定結果を示す．また，Table 1 に推 定結果の二乗平均誤差を示す . なお，表の值は各シミュ レーションを 10 回行ったときの平均值を示す.さらに， Table 1 では文献 [3] のロバストフィルタの結果も合わせ て示している．これらの結果より，UKF は外れ値を完 全に除去できず，推定結果に外れ值の影響が生じている ことがわかる . また , 文献 [3] のロバストフィルタは推 定值に突発的な誤差は生じないものの, 推定値との誤差 は大きくなっている．一方，RUKF は外れ値を除去し， 最も誤差が少ないことがわかる．

\section{4. おわりに}

本研究では， $l_{1}$ 正則化を UKF に適用することで外れ 值にロバストなUKF を提案した . また, 弚のパラメータ 設計問題が $l_{1}$ ラプラス分布の共分散推定問題に帰着でき ることを示し，シグマポイントを用いて推定した . 乥し て，これらの有効性を数值シミュレーションで示した．

謝辞

本研究は科学研究費助成事業基盤研究 (B) 24360166 から研究費の一部の支援を得ました .ここに感謝の意を 表します．

\section{参 考 文 献}

[1] J. Mattingley and S. Boyd: Real-time convex optimization in signal processing - Recent advances that

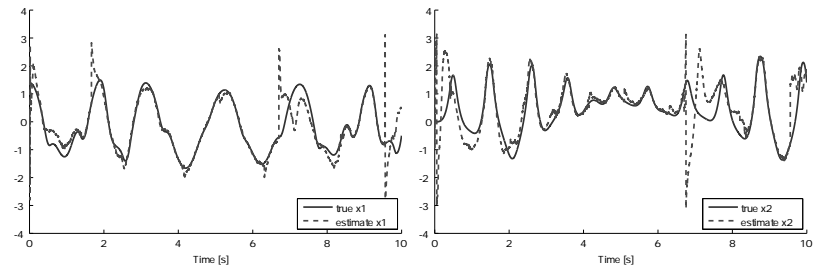

(a) estimate of $x_{1}\left(\theta_{1}\right)$

(b) estimate of $x_{2}\left(\theta_{2}\right)$

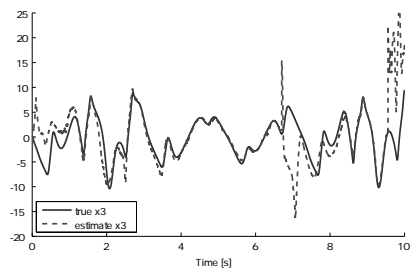

(c) estimate of $x_{3}\left(\dot{\theta}_{1}\right)$

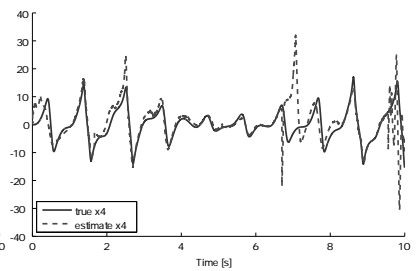

(d) estimate of $x_{4}\left(\dot{\theta}_{2}\right)$
Fig. 3 Estimates using UKF. The solid lines are true signals and dashed lines are estimates.

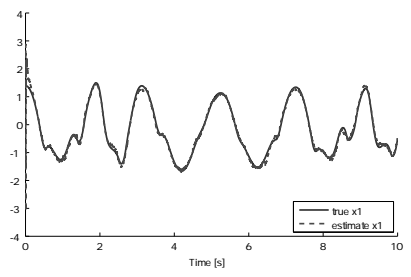

(a) estimate of $x_{1}\left(\theta_{1}\right)$ (b) estimate of $x_{2}\left(\theta_{2}\right)$
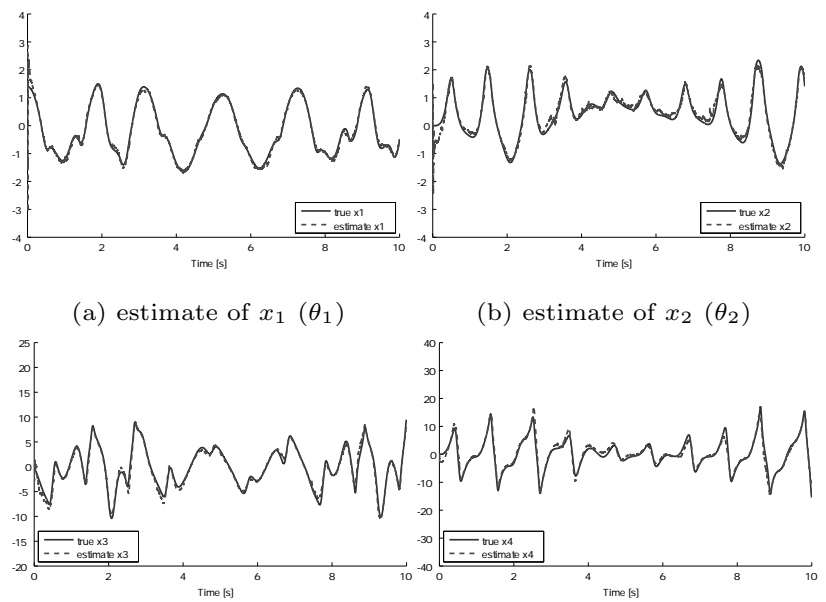

$\begin{array}{ll}\text { (c) estimate of } x_{3}\left(\dot{\theta}_{1}\right) & \text { (d) estimate of } x_{4}\left(\dot{\theta}_{2}\right)\end{array}$

Fig. 4 Estimates using RUKF. The solid lines are true signals and dashed lines are estimates.

make it easier to design and implement algorithms -; IEEE Signal Processing Magazine (2010)

[2] Y. Kaneda, et al.: Design method of robust Kalman filter via $l_{1}$ regression and its application for vehicle control with outliers; Proc. of IECON, pp. 2210-2215 (2012)

[3] A. Y. Aravkin, et al.: An $l_{1}$-laplace robust Kalman smoother; IEEE Trans. Automat. Contr., Vol. 56, No. 12, pp. 2898-2911 (2011)

[4] S. Julier, et al.: A new method for the nonliear transformation of means and covariances in filters and estimators; IEEE Trans. Automat. Contr., Vol. 45, No. 3, pp. 477-482 (2000)

[5] M. Idan and J. L. Speyer: Cauchy estimation for linear scalar system; IEEE Trans. Automat. Contr., Vol. 55, No. 6, pp. 1329-1342 (2010) 